\title{
Home-based Palliative Intervention to Improve Quality of Life in Children with Cancer: A Randomized Controlled Trial
}

Murti Andriastuti ( $\sim$ pricilia.gh@gmail.com )

Universitas Indonesia https://orcid.org/0000-0003-2258-6877

Pricilia G Halim

Rumah Sakit Dr Cipto Mangunkusumo

Elnino Tunjungsari

Rumah Sakit Dr Cipto Mangunkusumo

Dwi P Widodo

Rumah Sakit Dr Cipto Mangunkusumo

Research article

Keywords: home visits, palliative, pediatric, cancer, quality of life

Posted Date: December 16th, 2019

DOI: https://doi.org/10.21203/rs.2.18923/v1

License: @ (i) This work is licensed under a Creative Commons Attribution 4.0 International License.

Read Full License 


\section{Abstract}

Background: In these last few years, an integrated approach between palliative care (PC) and chronic and/or life-threatening conditions care have been widely used. Home-based PC service is developed to meet the needs of the patients at home, but hasn't been applied widely. This study is aimed to determine the benefit of integrated home-based PC in the quality of life (QOL) and symtomps intensity of Indonesian children with malignancies.

Method: A randomized controlled trial to compare the quality of life between patients who were given PC (a 3-month home visit) and those who were not (intervention vs control group) was conducted, each group containing 30 children with cancer aged 2-18 years old who were consulted to palliative team. Participants were randomly assigned into each group. In the first and twelfth week of the intervention, all patients were assessed with the Pediatric Quality of Life Inventory (PedsQLTM) questionnaire cancer module 3.0 (report by proxy or self-report). Symptoms intensity (pain, anorexia, sleep disturbance) were scored by using Edmonton Symptoms Assessment Scale (ESAS). Mean score and each dimension score of both group were compared and analyzed using bivariate analysis.

Results: A total 50 participants were included in analysis. Significant difference was found between two groups with average total score in control group 62.39 and intervention group $81.63(p<0.001)$. In the intervention group QoL tends to improve, whereas in the control group, those did not get palliative intervention, quality of life tends to decrease as the disease progress. The most improved aspect in QoL is pain and nausea $(p<0.001)$, followed by procedural anxiety $(p=0.002)$, treatment anxiety $(p=0.002)$, and worry $(p=0.014)$. Palliative intervention was found to be able to reduce sleep disturbances $(p=0.003)$ and anorexia $(p<0.001)$ significantly.

Conclusion: Home-based PC improved several aspects of the QOL and provide better symptoms management of children with malignancies. An early intervention concurrent with the underlying treatment is believed to be able to improve their quality of life.

Trial Registration: This study has been retrospectively registered in ClinicalTrials.gov ID: NCT04067687 (August, 22nd 2019).

\section{Background}

The medicine world has seen some significant development in treating chronic illnesses and lifethreatening conditions. However, morbidity levels are as high as ever, if not higher. ${ }^{1}$ This decrease in mortality is linked with the increase in patients' morbidity because of the improving life expectancy the longer patients undergo their treatment. During the treatment patients and their families will encounter various physical, psychological, and spiritual disturbances, lowering their quality of life as well as their treatment outcome. ${ }^{2}$ Palliative care (PC) is an essential component in the treatment of chronic and lifethreatening illness. Its purpose is to prevent and decrease patients' burden through early identification, 
assessment and treatment of symptoms as well as other problems such as physical, psychosocial, and spiritual. $^{3-5}$

At first, PC was only aimed at children in end-stage diseases, but now it has been used widely since the beginning of disease. ${ }^{5}$ Several studies have proven that PC could improve physical, psychosocial, quality of life (QoL), quality of end-of-life care, treatment cost, and even life expectancy. ${ }^{5-8}$ Palliative care could be given either in hospitals, communities, or in long-term care facilities such as at

home/homestay/clinic. ${ }^{9}$ In developed countries, most PC are given in patients' homes and long-term care facilities where patients stay. ${ }^{3}$ Home visits are believe to have such important roles in PC to provide a continuity of care and psychosocial support to both patients and their parents or guardians. ${ }^{10,11}$ Several healthcare facilities in developed countries have established home visit program in PC. ${ }^{10,12}$

In Indonesia, there hasn't been any studies to prove the advantages of giving PC and home visit program to children with malignancies. This research would be the first randomized trial in Indonesia which would prove the advantages of palliative integration with home visit model in children with malignancies.

\section{Method}

\section{Research Design and Sampling}

This study is a randomized controlled trial to compare the quality of life and symptoms intensity between children with malignancies who were given palliative intervention and those who were not. Research was conducted in Pediatric Health Department in Cipto Mangunkusumo Hospital, Jakarta, Indonesia, from January to June 2019. To see the difference between two independent population with $95 \%$ confidence interval and $80 \%$ power, minimum number of participants were 30 for each group (1:1 ratio). Mean difference of 20 is considered significant for QoL. ${ }^{13}$ Inclusion criteria consisted of pediatric patients with malignancies who were consulted to palliative team in Pediatric Health Department, Cipto Mangunkusumo Hospital, during the research period, all patients with malignancies aged 2-18 years old fulfilling the criteria for palliative care (score of $\geq 4$ in Cipto Mangunkusumo Hospital's palliative screening form), and patients and/or parents agreeing to palliative intervention. Patients lived outside Jakarta were considered unreachable, therefore excluded from this research. Sampling method was done by consecutive sampling, patients were divided into two groups randomly (intervention group $(A)$ and control group (B)), using blocked randomization (AABB) method.

\section{Intervention}

Patients were given home visits as the intervention. It was done by trained and certified medical professionals who were in charge of Cipto Mangunkusumo Hospital's Pediatric Palliative Care (PPC) team. Interventions were given for 3 months, by giving two-way communications between trained medical professionals, patient, and parents. It was divided into 6 visits (once every two weeks), focusing on educating parents on problem solving, symptoms management including the medications, self-care, 
communication, decision making, and continued care plan using standard procedures. Each session lasted about 60 minutes and could be done either at home or at their homestay. Hospitalization history of more than 7 days was not accounted into follow up period. Patients then were followed and evaluated for their QoL on the first and twelfth week of intervention. Symptoms intensity (pain, anorexia, and sleep quality) were evaluated at first and then at every visit. During their participation in this study, patients were being treated according to Cipto Mangunkunsumo Hospital's Pediatric Hematology-Oncology Division's treatment protocol. Participants in both group were not aware about any superiority of intervention during study.

\section{Assessment of Quality of Life and Symptoms Intensity}

Patients' quality of life was evaluated using Pediatric Quality of Life Inventory Questionnaire (PedsQL ${ }^{\mathrm{TM}}$ ) cancer module 3.0 which consisted of 8 dimensions (pain, nausea, procedural anxiety, treatment anxiety, worry, cognitive, physique, communication). Children aged 2-7 years old were being evaluated based on the questionnaires filled by parents, while children above 7 years old either had their questionnaires filled by parents or had help from their parents to fill the questionnaires themselves. The questionnaire itself consisted of close-ended questions in which the subjects needed to choose one number ranging from 04. Each question presented a problem, while the numbers were in line with how often said problem had arisen in the patients' daily lives, with 0 being "never", 1 being "almost never", 2 being "sometimes", 3 being "often", and 4 being "almost always". Each answer would be converted into scores; $0=100,1=75$, $2=50,3=25,4=0$. The scores in each dimension would be counted by doing a summation of the relevant questions, divided by the number of answered questions. If there were more than $50 \%$ unanswered questions, dimension would be excluded from the analysis. The total score would be obtained from the summation of scores from each answered question divided by the number of answered questions from each dimension. Higher scores meant better QoL. The respondent needs to be the same person throughout the study.

Symptoms intensity was evaluated using Edmonton Symptom Assessment Scale (ESAS). In this study we used only three most common symptoms; pain, anorexia, and sleep disturbances. The intensity was scored using numbers ranging from 0 to 10,0 being the lowest and 10 the highest intensity.

Questionnaires could be filled either by the patients (assisted by their parents), the parents themselves, or by the palliative team, based on patients' or parents' answers. The respondent needs to be the same person throughout the study as well.

\section{Statistical Analysis}

The results from this study were statistically analyzed using SPSS version 20.0. Bivariate analysis using Mann-Whitney formula was used to determine the mean difference of QoL and symptom intensity from the two groups in this study. The test was done with $95 \%$ confidence interval.

\section{Results}


During the time of this study, 60 participantss were enrolled. There were 4 participantss who were lost to be followed up in the control group by death, while there were 6 participantss in the control. By the end of this study, 50 participantss were included in the per protocol analysis (Figure 1).

No significant differences were found between the two groups for their sociodemographic and clinical characteristics, in exception for the anorexia score; control group's score differ significantly from the intervention group's (Table 1 ). From the assessment of the patients' quality of life, 41 subjects $(68,3 \%)$ answered the questionnaires by proxy while 19 subjects $(31,6 \%)$ answered by self-report.

\section{Quality of Life}

By the end of this study, 26 subjects from the control group and 24 subjects from the intervention group managed to pull through with the study. Intervention group's quality of life final score was higher $(81,63)$ than control group (62,39). Statistical analysis showed significant results with $p$ value $<0,001$.

Significantly improving functional areas were pain, nausea, procedure anxiety, treatment anxiety, and worry. Meanwhile, other functional areas such as physique, cognitive, and communication did not meet the required cut-off to make significant difference between the two groups. Results from the QoL assessment of the two groups can be seen in Table 2. 
Table 1

Participants' characteristics

\begin{tabular}{|c|c|c|}
\hline \multirow[t]{2}{*}{ Demographic Characteristics } & \multirow[t]{2}{*}{$\begin{array}{l}\text { Control } \\
\text { n (\%) }\end{array}$} & $\begin{array}{l}\text { Intervention } \\
\mathrm{n}(\%)\end{array}$ \\
\hline & & $\mathrm{n}(\%)$ \\
\hline \multicolumn{3}{|l|}{ Sex } \\
\hline Male & $14(46,7)$ & $21(70)$ \\
\hline Female & $16(53,3)$ & $9(30)$ \\
\hline \multicolumn{3}{|l|}{ Age (years old) } \\
\hline $2-4$ & $10(33,3)$ & $9(30)$ \\
\hline $5-7$ & $4(13,3)$ & $5(16,7)$ \\
\hline $8-12$ & $10(33,3)$ & $8(26,7)$ \\
\hline $13-18$ & $6(20)$ & $8(26,7)$ \\
\hline \multicolumn{3}{|l|}{ Diagnosis } \\
\hline Lymphoma & $1(3,5)$ & $1(3,5)$ \\
\hline Solid tumor & $17(58,6)$ & $12(37,9)$ \\
\hline Leukemia & $12(37,9)$ & $17(58,6)$ \\
\hline \multicolumn{3}{|l|}{ Disease duration } \\
\hline$<1$ year & $21(70)$ & $19(63,3)$ \\
\hline$\geq 1$ year & $9(30)$ & $11(36,7)$ \\
\hline \multicolumn{3}{|l|}{ End-of-life } \\
\hline Yes & $5(16,7)$ & $5(16,7)$ \\
\hline No & $25(83,3)$ & $25(83,3)$ \\
\hline \multicolumn{3}{|l|}{ Ongoing chemotherapy } \\
\hline Yes & $28(93,3)$ & $25(83,3)$ \\
\hline No & $2(6,7)$ & $5(16,7)$ \\
\hline Initial ESAS & Mean (SD) & Mean (SD) \\
\hline Pain & $2,43(1,92)$ & $3,2(2,62)$ \\
\hline Sleep disturbances & $2,07(1,84)$ & $2,03(2,22)$ \\
\hline
\end{tabular}




\begin{tabular}{|lll|}
\hline Demographic Characteristics & $\begin{array}{l}\text { Control } \\
\mathbf{n}(\%)\end{array}$ & $\begin{array}{l}\text { Intervention } \\
\mathbf{n}(\%)\end{array}$ \\
\cline { 3 - 3 } & & $\mathbf{n}(\%)$ \\
\hline Anorexia & $4,70(1,86)$ & $3,63(2,22)$ \\
\hline Karnofsky score & $75(14,80)$ & $75,17(19,2)$ \\
\hline Quality of life score & & \\
\hline Pain & $63,70(32,14)$ & $65,83(24,7)$ \\
\hline Nausea & $61,33(24,39)$ & $62,07(23,2)$ \\
\hline Procedure anxiety & $40,03(31,81)$ & $46,55(34,5)$ \\
\hline Treatment anxiety & $66,70(30,06)$ & $73,28(24,8)$ \\
\hline Worry & $74,70(21,82)$ & $71,28(27,1)$ \\
\hline Physique & $79,47(33,92)$ & $83,97(22,2)$ \\
\hline Cognitive & $75,17(22,41)$ & $66,10(19,5)$ \\
\hline Total & $65,64(16,47)$ & $65,45(14,6)$ \\
\hline & & \\
\hline
\end{tabular}

\section{Symptoms Intensity}

Based on the results of this study, the symptoms with significantly improving intensity with palliative intervention were sleep disturbances and anorexia. Mean score for sleep disturbances in the intervention group was $1,73 \pm 1,57$ while it was $2,87 \pm 2,21$ for control group $(p=0,003)$. Mean score for anorexia in the intervention group was $3,27 \pm 1,86$ while the control group had $5,07 \pm 1,82(p<0,001)$ (Table 3$)$. The final score for pain in the intervention group was $3,47 \pm 2,56$ while the score for control group was $2,48 \pm 1,86$. Statistical analysis showed insignificant difference between them with $p=0,123$. However, compared to the early phases of this study, the mean score for intervention group did decrease (from 3,20 in the early phase to 2,48 ). On the contrary, it was found that in the control group there was an increase in the intensity of pain (from 2,43 in the early phase to 3,47 ). 
Table 2

Patients' quality of life by the end of the study

\begin{tabular}{|llll|}
\hline Domain & Mean (SD) & \\
\cline { 2 - 4 } & Control $(\mathbf{n}=\mathbf{2 6})$ & Intervention $(\mathbf{n}=\mathbf{2 4})$ & $\mathbf{p}$ \\
\hline Pain & $56,23(26,75)$ & $86,04(25,37)$ & $<0,001$ \\
\hline Nausea & $51,92(21,17)$ & $82,83(21,15)$ & $<0,001$ \\
\hline Procedure anxiety & $41,04(31,83)$ & $68,48(27,22)$ & 0,002 \\
\hline Treatment anxiety & $67,69(30,09)$ & $93,13(11,14)$ & 0,002 \\
\hline Worry & $68,88(22,97)$ & $83,57(26,07)$ & 0,014 \\
\hline Physique & $82,54(29,07)$ & $92,43(15,26)$ & 0,357 \\
\hline Cognitive & $71,15(21,61)$ & $80,30(18,42)$ & 0,119 \\
\hline Communication & $61,00(27,99)$ & $67,69(29,55)$ & 0,315 \\
\hline Total & $62,39(15,75)$ & $81,63(14,61)$ & $<0,001$ \\
\hline
\end{tabular}

Table 3

Mean score for each symptom in the final phase of the study

\begin{tabular}{|llll|}
\hline Symptoms intensity & Mean (SD) & p \\
\cline { 2 - 3 } & Control & Intervention & \\
\hline Pain & $3,47(2,56)$ & $2,48(1,86)$ & 0,123 \\
\hline Sleep disturbance & $2,87(2,21)$ & $1,73(1,57)$ & 0,003 \\
\hline Anorexia & $5,07(5,07)$ & $3,27(1,86)$ & $<0,001$ \\
\hline
\end{tabular}

\section{Discussion}

Involving 60 pediatric patients with malignancy in the span of 12 weeks, this study was the first randomized controlled trial about the role of home-based pediatric palliative intervention in Indonesia. From statistical analysis, no significant difference was found out of the two groups' sociodemographic data. Initial assessment for quality of life in the intervention group showed no significant difference based on the statistical analysis of the total mean score and the entire dimensions as well (Table 1). Both groups in this study showed similar characteristic at the beginning of study.

In the final assessment, the intervention group had a more significant score compared to the control group. This shows that palliative intervention, concurrently done with treating the underlying disease 
could improve pediatric cancer patients' quality of life, similar with another study by Bakitas et al, which stated that early palliative intervention in adult patients could improve quality of life. ${ }^{5}$ Several other studies also stated similar results; that palliative intervention could provide better QoL and also improve the end-of-life stage. ${ }^{14,15-17}$ Palliative intervention should be preventive instead of curative, as well as improves quality of life by early identification, accurate assessment, and treatment of pain and other symptoms, such as physical, psychosocial, and spiritual. Health providers, together with patients and their families could decide the goal for care (curative or palliative). Palliative intervention could improve patients' outcome, including, but not limited to, physical, psychosocial, patients' satisfaction, even quality of life. $^{6-8,18}$

By the end of this study, the quality of life of the intervention group increased, while the control group it decreased. This showed that pediatric cancer patient tend to have lower quality of life as the disease progressed, and reaching its lowest during the end-of-life stage. ${ }^{19}$ Several other studies also stated that pediatric cancer patients would have decreased quality of life during its treatment course. ${ }^{20,21}$ Decreasing quality of life in children could result from a wide variety of factors, such as shock during the initial diagnosis reveal, followed by the course of the disease, as well as the inexplicable length of treatment. During its disease course, children would need to develop a defense mechanism shown in a variety of attitudes and mental states. This process would continue to progress if not intervened immediately. Quality of life would start decreasing during the first 3-5 months after diagnosis. Psychological problems, low self-worth, even depression issues often arise. ${ }^{19}$ The results of this study strengthen the belief to give palliative intervention on pediatric cancer patients, starting early in the disease progression along with the disease trajectory. It is extremely important for health providers to be able to comprehend the ideal QoL patient should have. ${ }^{22}$

Significantly improved functional areas include pain, nausea, procedure anxiety, treatment anxiety, and worry. The most common side effects in the treatment of pediatric cancer are pain and nausea. ${ }^{9}$ This study shows that palliative intervention would help improve the quality of life of these children by preventing pain and nausea worsening in accordance to the patients' disease treatment. Mahmood et al, also stated that early palliative consultation was indeed feasible in pediatric cancer patients, especially the high-risk ones. Palliative care could provide assistance on symptoms control and communication between parents, patients, and health providers. The physical aspect, cognitive, and communication did not improve significantly on the intervention group. Therefore, result in this study did not align with the theory in which palliative consultation could assist the communication between parents, patients, and health providers. ${ }^{23}$ Since this study did not involve child psychiatrists, such discrepancy is possible, because disruption in communication could not be treated optimally by the palliative team. Disruption in communication could be caused by the child's psychological disturbances due to lack of activities, frequent hospitalization, and dread of what the future would bring. ${ }^{19}$ This asserts the need for a child psychiatrist's role in the integrated palliative program. 
Most of the assessment for quality of life in this study was done by proxy. Self-report questionnaires were fewer in this study, because most of the subjects $(76,7 \%)$ were children under 12 years old. Various cognitive and verbal intelligence between each child made self-report more challenging to do. Based on the recommendation made by Varni et al, a questionnaire designed to be filled by parents/guardians should be used for small children, cognitive-impaired children, gravely ill children, or those who are too exhausted to fill one. Parents/guardians' questionnaires should replace self-report questionnaires, when the child is able to fill it themselves or using their own perspectives. ${ }^{24} \mathrm{~A}$ meta-analysis stated that in general, there is a good amount of synergy between the parents and the children's reports, with correlation score of $r>50$ in physical, functional, and symptoms aspect. ${ }^{25}$ In this study, PedsQL ${ }^{\text {TM }}$ cancer module 3.0 was used using the domains of functional and symptoms, making the synergy between parents and children's reports considered good enough.

Sleep disturbances and anorexia were the significantly reduced symptoms intensity in this research. One of the major roles of palliative care was symptoms treatment or management while patients were being cared for. In cancer patients, the five most common symptoms are pain, anorexia, sleep disturbances, difficulty breathing, and exhaustion. ${ }^{9}$ Palliative approach has the role to bridge non-medical problems that arise while patients undergo treatment, especially in the cases of unavailable drugs or non-optimal medical treatment. ${ }^{4}$ The use of antiemetic agents would be limited due to the restriction of our national drug formulary (only given for three days after chemotherapy). The use of sedatives or tranquilizer in children are only recommended in certain cases, under the supervision of child psychiatrists. This study proved that home-based palliative intervention could be one of the modalities to be used in managing such symptoms in pediatric cancer patients.

The final pain score between intervention group was found to be lower than the control group, even though statistically insignificant. We found that there was also a form of symptomatic treatment given to all subjects of our study (including the control group) by giving analgesics, as per the standard of pain treatment, since pain is one of the obligatory symptoms to be treated with medicines. However, the decreasing pain score of the intervention group lower than those in the control group, showed that palliative intervention could help reduce pain in synergy with medical intervention. The combination of medicinal therapy and palliative approach would elucidate better pain management for pediatric cancer patient.

Cancer treatment approach does not only come from the medical aspect, but also other symptoms-be it physical, psychosocial, emotional, and spiritual. All of them should be tended to, received adequate treatment in order to maintain patients' quality of life. ${ }^{19}$ Integrated palliative care gives health providers chances to deliver comprehensive treatment for patients, consisted of aspects such as psychological, developmental, spiritual, and better symptoms management. American Academy of Pediatrics (AAP) had offered an integrated, interdisciplinary approach in order to achieve a competent, compassionate care. Palliative approach is offered during the time of diagnosis up until the end of the disease's progresseither in health or death. ${ }^{26}$ Ideally, pediatric cancer patients should automatically meet the criteria for 
palliative care, even if it's still early on the progress of the disease. But in fact, many clinicians do not have enough understanding about the importance and the roles of early palliative care initiations on children with chronic or life-threatening illnesses. ${ }^{27,28}$ Moreover, clinicians working on facilities with hospitalization services only have limited time to dive in the communities. Hospitals are not fit for managing patients' and their families' psychosocial problems. ${ }^{29}$ Hospital-based oncologic treatment is limited to the hospital, and are not considered to be able to give the continued care for physical, psychosocial, emotional, and spiritual symptoms patients and their families are probably going through. ${ }^{12}$ Those bariers made optimal PPC services are difficult to be achieved. Home-based PC is way to overcome it and through it we can helps patients and their families manage the symptoms, reduce anxieties as well as psychological distress. ${ }^{27}$ It is proved in this study that palliative intervention in the form of home visits are beneficial for improving quality of life as well as better symptoms management for pediatric cancer patients.

\section{Conclusion}

Integrated home-based palliative care is beneficial for improving quality of life as well as better symptoms management for pediatric cancer patients. We recommend this intervention to be applied for all pediatric cancer patients.

\section{List Of Abbreviations}

AAP

Amecian Association of Pediatric

ESAS

Edmonton Symptom Assessment Scale

PedsQL ${ }^{\text {TM }}$

Pediatric Quality of Life Inventory

PC

Palliative Care

PPC

Pediatric Palliative Care

QoL

Quality of Life

\section{Declarations}

\section{Ethics approval and consent to participate}

This study was approved by Fakultas Kedokteran Universitas Indonesia's Ethics Committee with the number of $1368 /$ UN2F1/ETIK/XI/2018. This study was also enlisted in ClinicalTrials.gov with the ID of 
NCT04067687. Written and signed informed consent were obtained from parents and assent were obtained from children before the commencement of study.

\section{Consent to publish}

Not applicable

\section{Availability of data and materials}

The datasets used and/or analysed during the current study are available from the corresponding author on reasonable request.

\section{Competing interests}

The authors declare that they have no competing interests

\section{Funding}

This research was funded by research grant of Faculty of Medicine Universitas Indonesia, Cipto Mangunkusumo Hospital, Jakarta. The funder contributes in supporting research funding without any further work in the research.

\section{Authors' contributions}

MA : Planning the research project, analysis, writing, edited the manuscript with significant intellectual contribution and approved the final script, PGH: Planning the research project, data collection, analysis, and writing the manuscript, DPW : Edited the manuscript with significant intellectual contribution and approved the final script, ET : Data collection.

All the authors have read and approved the manuscript.

\section{Acknowledgements}

The authors would like to thank all palliative team at Cipto Mangunkusumo Hospital who help to gathered data and make assessment.

\section{Authors' information}

${ }^{1}$ Department of Child Health, University of Indonesia Hospital, Cipto Mangunkusumo Hospital, Faculty of Medicine, Universitas Indonesia, Jakarta

2,4 Department of Child Health, Cipto Mangunkusumo Hospital, Faculty of Medicine, Universitas Indonesia, Jakarta

${ }^{3}$ Pediatric Nursing, Cipto Mangunkusumo Hospital, Jakarta 
*Correspondence : pricilia.gh@gmail.com

\section{References}

1. Ramchandran K, Tribett E, Dietrich B, Von Roenn J. Integrating palliative care into oncology: A way forward. Cancer Control. 2015;22:386-95.

2. Greer JA, Jackson VA, Meier DE, Temel JS. Early integration of palliative care services with standard oncology care for patients with advanced cancer. Ca Cancer J Clin. 2013;63:349-62.

3. Zhi WI, Smith TJ. Early integration of palliative care into oncology: evidence, challenges and barriers. Ann Palliat Med. 2015;4:122-31.

4. World Health Organization. WHO Definition of Palliative Care. 2013. Tersedia di : http://www.who.int/cancer/palliative/en/. Accessed 19 January 2018.

5. Bakitas M, Lyons KD, Hegel MT, Balan S, Brokaw FC, Seville J, et al. The project ENABLE II randomized controlled trial to improve palliative care for patients with advanced cancer. JAMA. 2009;302:741-49.

6. Hui D, Kim SH, Roquemore J, Dev R, Chisholm G, Bruera E. Impact of timing and setting of palliative care referral on quality of end-of-life care in cancer patients. Cancer. 2014;6:1743-49.

7. Temel JS, Greer JA, Muzikansky A. Early palliative care for patients with metastatic nonsmall-cell lung cancer. N Engl J Med. 2010;363:733-42.

8. Yennurajalingam S, Urbauer DL, Casper KL. Impact of a palliative care consultation team on cancerrelated symptoms in advanced cancer patients referred to an outpatient supportive care clinic. J Pain Symptom Manage. 2011;41:49-56.

9. Kelley AS, Morrison RS. Palliative care for the seriously ill. N Engl J Med. 2015;373:747-55.

10. Shoemaker LK, Aktas A, Walsh D,Hullihen B, Khan MIA, Russell KM, et al. A pilot study of palliative medicine fellows' hospice home visits. American Journal of Hospice \& Palliative Medicine. 2012;29:591-8.

11. Chong LA, Khalid F. Paediatric palliative care at home: a single centre's experience. Singapore Med J. 2016;57:77-80.

12. Chong PH, De Castro Molina JA, Teo K, Tan WS. Paediatric palliative care improves patient outcomes and reduces healthcare costs: evaluation of a home-based program. BMC Palliative Care. 2018;17:18.

13. Varni JW, Burwinkle TM, Katz ER, Meeske K, Dickinson P. The PedsQL ${ }^{T M}$ in pediatric cancer reliability and validity of the pediatric quality of life inventory ${ }^{\mathrm{TM}}$ generic core scales, multidimensional fatigue scale, and cancer module. Cancer. 2002;94:2090-2106.

14. Davis MP, Temel JS, Balboni T, Glare P. A review of the trials which examine early integration of outpatient and home palliative care for patients with serious illnesses. Ann Palliat Med. 2015;4:99121. 
15. Brumley R, Enguidanos S, Jamison P. Increased satisfaction with care and lower costs: results of a randomized trial of in-home palliative care. J Am Geriatr Soc. 2007;55:993-1000.

16. Gade G, Venohr I, Conner D. Impact of an inpatient palliative care team: a randomized control trial. J Palliat Med. 2008;11:180-90.

17. Pantilat SZ, O'Riordan DL, Dibble SL. Hospital-based palliative medicine consultation: a randomized controlled trial. Arch Int Med. 2010;170:2038-40.

18. Zimmermann C, Swami N, Krzyzanowska M. Early palliative care for patients with advanced cancer: A cluster-randomised controlled trial. Lancet. 2014;383:1721-30.

19. Vlachioti E, Matziou V, Perdikaris P, Mitsiou M, Stylianou C, Tsoumakas K, et al. Assessment of quality of life of children and adolescents with cancer during their treatment. Japanese Journal of Clinical Oncology. 2016;46:453-61.

20. Ward-Smith P, Hamlin J, Bartholomew J, Stegenga K. Quality of life among adolescents with cancer. J Pediatr Oncol Nurs. 2007;24:166-71.

21. Landolt M, Vollrath M, Niggli F, Gnehm H, Sennhauser F. Health-related quality of life in children with newly diagnosed cancer: a one year follow-up study. Health Quality Life. 2006;4:63.

22. Evan EE, Calonico E, Tan J, Zeltzer LK. A qualitative approach to understanding quality of life in pediatric palliative care. J Palliative Care Med 2012;5:1-6.

23. Mahmood L, Ann D, DolanJ, Casey D, Korones Early palliative care involvement for children with cancer. Journal of Clin Oncol. 2014;32:26.

24. Varni JW, Limbers C, Burwinkle TM. Literature review: health-related quality of life measurement in pediatric oncology: hearing the voices of the children. Journal of Pediatric Psychology. 2007;32:1151-62.

25. Eiser C, Morse R. Can parents rate their child's health-related quality of life?: Results from a systematic review. Quality of Life Research. 2001;10:347-57.

26. Friedrichsdorf SJ, Postier A, Dreyfus J, Osenga K, Sencer S, Wolfe J. Improved quality of life at end of life related to home-based palliative care in children with cancer. Journal of Palliative Medicine. 2015;18:143-50.

27. Basol N. The Integration of palliative care into the emergency department. Turk J Emerg Med 2015;15:100-7.

28. Cheng BT, Rost M, De Clercq E, Arnold L, Elger BS, Wangmo T. Palliative care initiation in pediatric oncology patients: A systematic review. Cancer Medicine. 2019;8:3-12.

29. Allo JA, Cuello D, Zhang Y, Reddy SK, Azhar A, Bruera E. Patient home visits: measuring outcomes of a community model for palliative care education. J of Palliative Medicine. 2016;19:271-8.

\section{Figures}




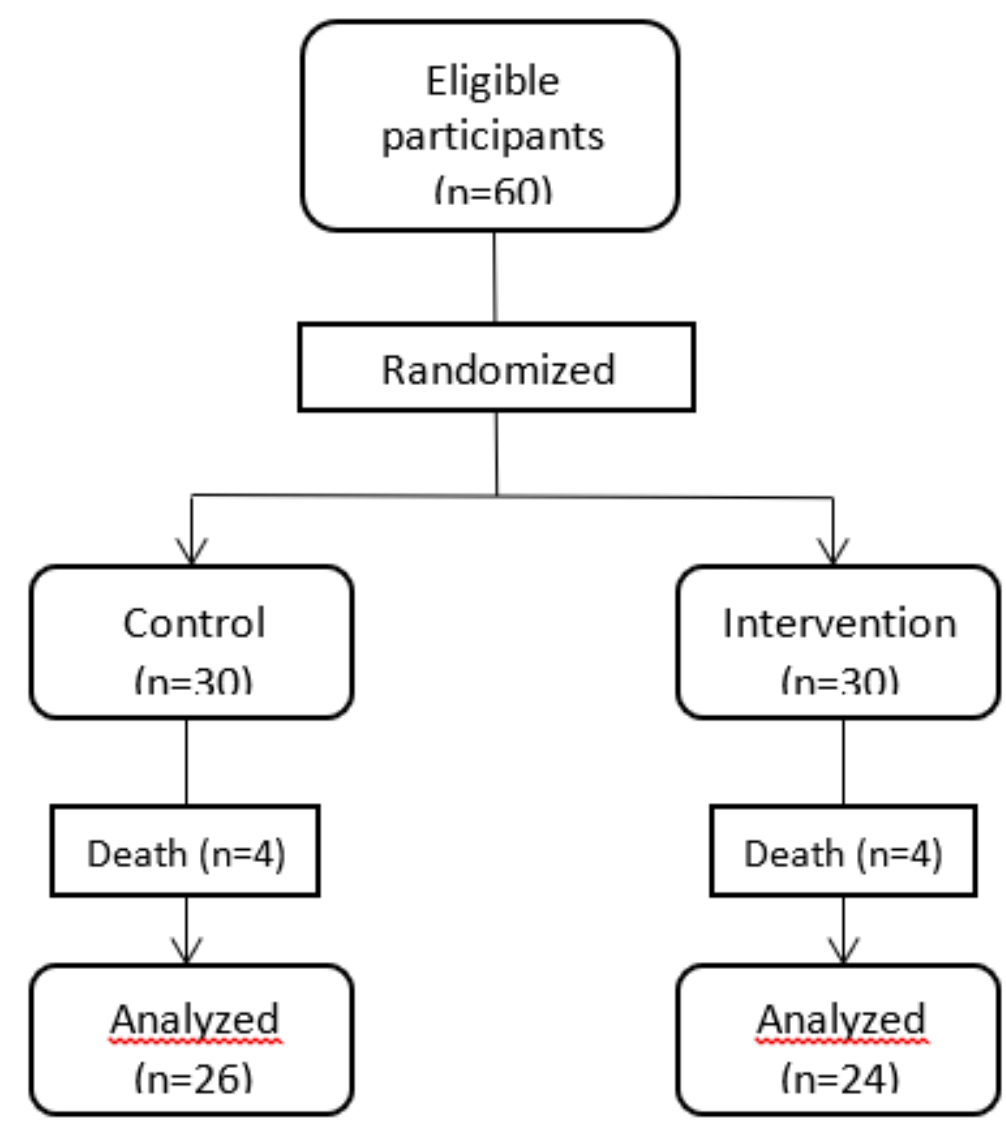

Figure 1

Participants enrollment 